\title{
Temas Fundamentais na Escola da Infância, de Ligia de Carvalho Abões Vercelli; Cristiano Rogério Alcântara (org).
} Jundiaí, São Paulo: Paco, 2017. 148 p.

Simone Eliane dos Santos Pessanha Mestranda do Programa de Gestão e Práticas Educacionais da Universidade Nove de Julho. São Paulo - SP - Brasil simone.leozinho@gmail.com

presente obra pertence a série Práticas Pedagógicas e a Formação Con-
tinuada na Escola da Infância, organizada por Ligia de Carvalho Abões Vercelli e Cristiano Rogério Alcântara. Vercelli é doutora e mestre em educação, graduada em Psicologia e em Pedagogia, Docente do curso de Pedagogia e do Programa de Mestrado em Gestão e Práticas Educacionais (Progepe) na Universidade Nove de Julho (Uninove). Alcântara é doutor em Língua Portuguesa, mestre em Ciência da Informação, Pedagogo, formado em Letras e Literatura brasileira e portuguesa. Atualmente, atua como Diretor Regional da Educação Infantil do Município de São Paulo.

A série é composta por três volumes, sendo que, cada um deles, apresenta resultados de pesquisas de mestrado concluída ou em andamento, além de relatos de práticas de professores/as que lecionam em instituições de educação básica das redes pública, municipal e estadual da grande São Paulo e do ABC. Os títulos dos volumes são os seguintes: Práticas Pedagógicas e a Formação Continuada na Educação Infantil 
TEmas Fundamentais NA Escola da InfânCia, DE Ligia de Carvalho ABÕes VerCELLi; CRISTIANo Rogério AlCÂNTARA (ORG)

I (vol. 1), Práticas Pedagógicas e a Formação Continuada na Educação Infantil II (vol.

2) e Temas Fundamentais na Escola da Infância (vol. 3).

O volume 3, que ora resenhamos, denomina-se Temas Fundamentais na Escola da Infância, é composto por oito capítulos, cada um deles escrito por diferentes autores. Tratam-se de textos que discutem a concepção de criança que fundamenta o trabalho pedagógico, onde a criança é vista como um ser capaz de construir conhecimentos e cultura, reafirmando as práticas pedagógicas que são efetivadas nas unidades educativas nas quais os autores atuam.

$\mathrm{Na}$ apresentação, Vercelli e Alcântara ressaltam que os textos são fruto de discussões ocorridas no Grupo de Pesquisa em Educação Infantil e Formação de Professores (Grupeiforp), pertencente ao Programa de Mestrado em Gestão e Práticas Educacionais da Universidade Nove de Julho (Progepe/Uninove).

No prefácio, a Professora Dra. Patricia Vasconcelos Almeida, docente da Universidade Federal de Lavras, ressalta a necessidade de publicações com temáticas que tratem sobre a formação dos professores da educação infantil, e assim, faz uma paráfrase com uma história do escritor uruguaio Eduardo Galeano que se chama "A função da arte", comparando os conhecimentos que as crianças podem descobrir no universo escolar e com o cotidiano da escola [...] "já que, muitas vezes, diante da imensidão do conhecimento, o aluno, não com essas palavras, mas por muitas vez es, pede ao professor: “- Me ajuda a olhar!”. [...] (ALMEIDA, 2017, p. 9)

O primeiro capítulo, intitulado "Projeto Amigos da Natureza: uma relação entre creche e comunidade no município de Santo André”, Ligia de Carvalho Abões Vercelli e Talita Penelope Rodrigues da Silva, discutem a parceria estabelecida entre escola e comunidade, como primordial para uma educação de qualidade. As autoras ressaltam que a responsabilidade social é fundamental e contribui para a melhoria da qualidade 
de vida da sociedade, por isso, deve estar de acordo com as necessidades da comunidade. As autoras relatam que houve a caracterização da comunidade, para que pudesse ser analisada as práticas da creche para que o Projeto Político Pedagógico (PPP) pudesse ser construído, identificando os problemas com relação ao local por onde as crianças transitam. Uma das ações efetivas da creche foi o Projeto Amigos da Natureza, que de forma lúdica, os educadores proporcionaram ações de conscientização sobre o problema do lixo na comunidade. Vercelli e Silva, apontam que a comunidade local e a creche se mobilizaram e houve conscientização como possibilidade de reflexão sobre o meio ambiente e reciclagem, as ruas da comunidade permanecem mais limpas e a escola está preservada e é motivo de orgulho para o entorno escolar.

Eunice Ramos de Carvalho Fernandes, no segundo capítulo intitulado "Educação infantil: a construção do número pela criança”, apresenta as formas e as atividades que proporcionam as crianças a obtenção da construção do número. A autora aponta de forma muito positiva, que a construção das operações e do conceito de número se inicia desde a mais tenra infância e está inserida na escola e em todo o cotidiano da criança. Para compreender os números, as crianças vão adquirindo o entendimento necessário e passam a perceber a importância exercida pelos números em seu meio social, e para isso, são necessários estímulos. Fernandes destaca que, para a construção dos conhecimentos matemáticos por parte da criança, as professoras podem propor atividades variadas que despertem a imaginação e o cognitivo, dessa forma, o aprendizado e a construção do pensamento lógico matemático será apreendido de forma efetiva.

No terceiro capítulo "A leitura na educação infantil sob o olhar freiriano: uma análise crítica da realidade", Thiago Valim Oliveira, analisa a alfabetização precoce que tem ocorrido em muitas escolas de crianças pequenas, oferece sugestões de atividades lúdicas para serem trabalhadas na escola. $\mathrm{O}$ autor se apoia em algumas leis para apre- 
Temas Fundamentais na Escola da Infância, de Ligia de Carvalho AbÕes VERCELLi; CRISTIANO Rogério ALCÂNTARA (ORG)

sentar conceitos importantes da educação infantil, como por exemplo, o desenvolvimento integral da criança. Oliveira, também aborda que o conhecimento de mundo que a criança carrega para a escola precisa ser acolhido pelo educador para que seu aprendizado seja efetivo e significativo; também aborda o conceito de educação bancária que está ultrapassado, mas ainda permanece em algumas instituições. Desta forma, o autor destaca que a brincadeira é importante, visto que possibilita o aprender a ler nas situações interativas do contexto social.

O capítulo quatro, intitulado "Nem feio nem bonito: o olhar do professor para as produções infantis", Angélica de Almeida Merli, apresenta a relevância da coordenação pedagógica no trabalho dos fazeres docentes e sua contribuição para a arte na Educação Infantil com possibilidades formativas. A autora relata uma experiência vivenciada por ela junto a formação docente no trabalho com a expressão artística, uma vez que declara não ter dotes artísticos, mas que a formação oferecida à ela mudou o seu olhar para a arte e possibilitou propostas inusitadas para o trabalho com as crianças. No decorrer do texto a autora faz seu relato sobre o curso que participou com duas professoras da Escola Municipal de Educação Infantil (Emei) na qual era coordenadora pedagógica, deixando o julgamento de feio e/ou bonito de lado, para que pudessem aguçar o olhar das crianças com o novo, proporcionando a imaginação e a criatividade. Merli, precisou repensar a sua própria prática, porém, isso também envolvia o pensar a prática das professoras para redimensionar suas ações. Ela declara que esse processo foi fundamental para sua formação, visto que, foi preciso oferecer às crianças materiais e propostas diversas, possibilitando o criar e recriar das fantasias infantis, dessa forma, as professoras que se propuseram a oferecer novas propostas às suas turmas, também aprenderam por meio de métodos diferenciados e de novos olhares.

O quinto capítulo intitulado "Educação infantil: relações étnico-raciais e formação docente", Moacir Silva de Castro, aborda algumas concepções de criança e infância, 
para que possa melhor compreender a criança pequena na sociedade e no contexto escolar, por isso, o trabalho pedagógico da escola da infância tem importância educativa nas relações etnicorraciais. O autor aborda a categoria de criança ou infância que acontecem nas diversas sociedades e isso, nos leva a refletir as diferenças que são encontradas nos diversos contextos históricos, e que, dependem das relações políticas, cultural e econômica de cada povo, em um determinado tempo e espaço. Castro também ressalta que o docente da educação infantil, escolas e comunidade escolar, precisam de formação para tratar das questões referentes a diversidade étnica, porque a docência é uma ação educativa e é constituída mediante relações sociais, é preciso que os profissionais garantam os direitos das crianças negras previsto em lei para que estes se efetivem, assegurando às crianças o pleno desenvolvimento. Ressalta o artigo $5^{\circ}$ das Diretrizes Curriculares, a Lei 10.639/2003 e 11.645/2008, Plano Nacional de Educação (PNE 2014-2024), Plano Nacional de Educação em Direitos Humanos (PNEDH), são excelentes exemplos para uma educação de qualidade, que somente é significativa quando a criança sente motivação e interesse, visto que o conteúdo é relevante e mediante o contexto da criança, ela aprende e apreende, e atinge os objetivos qualitativos da educação.

No sexto capítulo "Discutindo a construção de valores na Educação Infantil”, Sandra Helena Loureiro Hoyler e Silvana Monteiro Gondim, discutem a construção de valores na educação infantil e como podem ser trabalhados em atividades de rodas de conversa, brincadeiras e contação de histórias. As autoras abordam a construção dos valores pautadas em Mario Sergio Cortella e outros educadores. Hoyler e Gondim, descrevem que a construção dos valores das crianças precisa ser desenvolvida desde cedo pelos pais, família e escola, dessa forma, a criança aprenderá a ser responsável pelos seus comportamentos e ações. Elas se apoiam em Freire para abordar a educação pautada no respeito, por ser um princípio básico para a convivência do ser humano em 
sociedade; professores e crianças devem aprender uns com os outros dentro de princípios éticos e dialógicos, possibilitando a troca de ideias e informações.

"Aulas de trabalho pedagógico coletivo: ações contra a mediocridade", é o título do capítulo sete, escrito por Amanda Maria Franco Liberato e Sueli Julioti. As autoras abordam a questão da mediocridade em espaços que são destinados à formação continuada, e que acabam sendo subutilizados para recados burocráticos. As autoras fazem uma apresentação sobre a concepção de Aulas de Trabalho Pedagógico Coletivo (ATPC), que são horas destinadas às aulas propriamente ditas que devem equilibrar o trabalho dos professores dentro da carga horária, para a correção dos trabalhos e aperfeiçoamento dos docentes. Liberato e Julioti ressaltam que o espaço fundamental de formação do professor está sendo reduzido e desmotivando o educador, visto que, a ênfase dessas reuniões acaba recaindo para repasse de orientações desnecessárias que não tem relação com o cotidiano e aperfeiçoamento do professor, essas orientações muitas vezes advindas das Diretorias de Ensino, são repassadas pelos coordenadores como recados.

No último capítulo "Tecnologias da informação e da comunicação: o aplicativo Scratch em foco", Dalva Célia Henriques Rocha Guazzelli, Élida Ferrari Penhalver e Lucimara de Souza Teixeira, apresentam o aplicativo Scratch, e apontam como ele pode colaborar no desenvolvimento do raciocínio lógico de crianças do $5^{\circ}$ ano do ensino fundamental; propõem diálogos com o uso de metodologias aliadas à tecnologia, proporcionando competências relevantes para o desenvolvimento da criança. De forma criativa e mediante a realidade da criança, as autoras fazem uso do Scratch, como forma de desenvolver a lógica e o raciocínio na educação básica. As crianças aprendem a pensar criticamente e também trabalhar colaborativamente. Guazzelli, Penhalver e Teixeira, tratam a questão das tecnologias da informação na educação de forma criativa, pois 
mostram que as crianças precisam de experiências novas para sentirem motivação para aprender, e o aplicativo "Scratch" possibilita essas descobertas.

A obra apresentada tem grande relevância e interessa não somente a professores, mas a todos aqueles que pesquisam sobre temas como práticas pedagógicas e formação continuada para professores da escola da infância. 